\title{
Alimentación, ocio y cultura en el pazo de Goiáns en el siglo XVIII
}

\author{
José MARÍA VÁzQUez LIJÓ \\ UNIVERSIDAD DE LA CORUÑA \\ Feeding, leisure time and culture in the pazo of Goians \\ (17 $7^{\text {th }}$ and $19^{\text {th }}$ centuries)
}

\begin{abstract}
RESUMEN
En esta comunicación se analizan algunos aspectos del micro cosmos cultural de un pazo gallego, el de Goiáns, cuya excepcional ubicación a orillas de la ría de Arousa dota de alto valor añadido a este solar con espacios singulares como pesquera y embarcadero. Los inventarios de bienes de la casa informan de varios indicadores culturales de las elites (libros, juegos, obras artísticas, instrumentos musicales) y otros, como la alimentación, pueden estudiarse gracias a la documentación contable. El breve esplendor material del pazo parece datarse a mediados del siglo XVIII coincidiendo con la exitosa promoción social de los señores de Goiáns y sus hijos consecuencia de un cúmulo de factores (relaciones familiares, poder económico, bodas ventajosas, educación privilegiada...). La carrera militar de los sucesivos dueños les obligó a residir allí donde ejercían estos empleos y Goiáns pasó a ser una segunda residencia, cada vez más vacía de vida y de muebles, convirtiéndose a partir de la década de 1820 en un simple centro de administración de rentas.
\end{abstract}

\section{PALABRAS CLAVE}

Hidalguía, alimentación, vida cotidiana, cultura, siglo XVIII

\section{ABSTRACT}

This report analyzes some relevant points about the cultural microcosm of a Galician Pazo (that of Goians). Its ideal situation, on the banks of the Ría de Arousa, provides an added value to this land with unique spaces such as a fisherie and a pier. Inventories of the household goods give a number of cultural indicators of the elite (books, games, artwork, musical instruments) and other factors, such as meals, can be studied thanks to accounting documentation. The Pazo reached its peak in the mid-eighteenth century coinciding with the successful social promotion of the lords of Goians and their children due to a combination of factors (family relations, wealth, marriages of convenience, a privileged education) The military careers of the subsequent owners forced them to move away and live wherever they exercised their jobs. This way Goians became a second residence, increasingly empty of life and furniture. In the 1820s, the building became just a property management center.

\section{KEYWORDS}

little nobility, feeding, daily life, culture, 18th century 


\section{INTRODUCCIÓN}

El pazo de Goiáns, situado en la parroquia coruñesa de Lampón (Boiro), constituye un notable símbolo del poder de la hidalguía en el Barbanza, una comarca en la que los señores de la casa de Goiáns, cuyo mayorazgo data de 1552, percibieron abundantes rentas forales y poseyeron otros pazos. La preeminencia de esta familia noble fue absoluta en el coto homónimo del que fueron mayores hacendados y señores jurisdiccionales, ejerciendo además como presenteros del curato de Lampón. Con el propósito de perpetuar la memoria del linaje, mandaron esculpir escudos heráldicos que hoy constituyen prácticamente el único elemento decorativo en los paramentos del pazo, cuya autoría, como la de la mayoría de estas edificaciones, es anónima. A diferencia de otros enclavados en el litoral con muros abiertos aprovechando las benignas condiciones climáticas, en Goiáns no encontramos loggias ni pórticos, ni tampoco balcones colgantes sobre ménsulas. Esta falta de brillo arquitectónico se ve compensada por el alto valor paisajístico de la amplia finca del pazo cuya privilegiada situación en la ribera de la ría de Arousa explica la existencia de dos construcciones excepcionales: la pesquera y el embarcadero.

Este conjunto, declarado Bien de Interés Cultural y hoy de titularidad pública, fue propiedad de una rama del linaje de los Caamaño que comenzaron a señorear Goiáns en el siglo XVIII, el período mejor conocido de la historia del pazo gracias a la información aportada por el fondo documental de dicha familia hidalga1. Basándonos en los inventarios de bienes y en las cuentas de esta casa, nuestro análisis se focaliza en la vida cotidiana en dicho escenario rural, particularmente en los indicadores culturales que caracterizan a estos señores como elites. Formaron parte de un heterogéneo y numeroso grupo social, el de la hidalguía gallega que presentó grandes diferencias internas en volumen de rentas y en cantidad de vasallos ${ }^{2}$. Si atendemos a este último parámetro, don Vicente Caamaño Gayoso, señor de Goiáns entre 1771 y 1800 , se sitúa en el segmento de los 85 hidalgos con una media de 119 vasallos a enorme distancia del escalafón superior ocupado por siete nobles titulados con una media de 2.481 vasallos. Pero este noble, poseedor de varios mayorazgos que culminaría su carrera en la Armada con el rango de brigadier, muy probablemente por su educación, por sus ingresos y por su capital familiar y en relaciones sociales gozó de un nivel de vida superior al de ese grupo. Don Juan José Caamaño Pardo, primogénito y sucesor del anterior, se

1 Archivo de la Diputación de Pontevedra (ADP). Arquivo Caamaño. Este fondo está compuesto por 138 unidades de instalación, cuyas datas extremas son 1411-1895. Ha sido la principal fuente documental del que es hasta hoy el principal estudio sobre la casa de Goiáns. J. M. VÁZQUEZ LIJÓ (2012). Luces sobre a casa de Goiáns a finais do Antigo Réxime. En prensa.

2 Los enfoques socio-económicos sobre la hidalguía gallega son abundantes. Menos atención se ha prestado a los aspectos culturales. Deben destacarse las contribuciones historiográficas de Ramón Villares, Pegerto Saavedra, Víctor Migués y Antonio Presedo. 
casó con la Condesa de Maceda, integrante de esa cúspide ${ }^{3}$. Se agrandaba pues la fama y el honor de la familia que venía señoreando Goiáns desde hacia varias generaciones, mientras que el pazo homónimo había pasado a ser una segunda residencia con el paso del tiempo más y más desatendida. En apenas un puñado de décadas este pazo transita penosamente de un relativo esplendor a un ocaso casi absoluto, muy visible en la década de 1820, arruinado en parte, deshabitado y prácticamente desnudo en sus interiores.

En gran medida, esta escalada social se cimentó en el ventajoso matrimonio entre don Juan Antonio Caamaño y Lamas y doña María Ventura Gayoso y Arias, hija del Vizconde de Oca don Andrés Gayoso Ozores, alférez mayor y regidor de las ciudades de Ourense y Santiago, y de doña Constanza Arias Ozores, Condesa de Amarante y Marquesa de San Miguel das Penas y de la Mota. Esta pareja dio a sus hijos una educación privilegiada, primero en colegios jesuitas y luego ampliada, según los destinos de cada uno, en las Universidades de Valladolid y de Salamanca, en el Seminario de Nobles de Madrid, o en la Academia de Guarda Marinas de Cádiz. También cuidó del futuro de sus hijas, unas bien dotadas para monjas y otras casadas con hombres de igual o superior posición. En el ocaso de sus días don Juan Antonio Caamaño quiso recordarles «la carrera y estado en que los puse privándome de su compañía en su tierna hedad con gastos crezidos que muchas vezes exzedieron a mis fuerzas». Sintetizando al máximo la biografía de algunos de estos vástagos, entre los que también se incluyó el mencionado Vicente,

- Joaquina llegó a abadesa de San Paio de Antealtares, el principal cenobio benedictino gallego

- Mariana tuvo por esposo a don Gaspar de Quirós, caballero de Cristo, del Santo Oficio de Coimbra, y dueño de varios mayorazgos en Portugal

- María Teresa, que cultivó la poesía y la amistad del padre Isla y del conocido cura de Fruime, nombre propio de las letras gallegas, se casó con el Conde de Lacy, aristócrata irlandés que llegó a embajador de España en Rusia, consejero de Guerra y Capitán General de Cataluña

- Jacobo fue consejero de Órdenes después de que servir una magistratura en la Audiencia de Valencia

- Ramón, amigo del célebre José Cadalso, fue caballero de Malta, isla en la que falleció en 1785 cuando estaba al frente de la embajada española, y

- José Caamaño y Gayoso que, tras ser promovido por el Conde de FernánNúñez — con quien trabó amistad en el Real Seminario de Nobles de Madrid y del que fue secretario en la embajada de Lisboa-, ganó plaza de ministro plenipoten-

${ }^{3}$ A. EIRAS ROEL (1989). «El Señorío gallego en cifras: nómica y ranking de los señores jurisdiccionales». Cuadernos de estudios gallegos, T. 38, n. 103, pp. 127-133. 
ciario ante los Cantones Suizos, ascendió a teniente general y tuvo el honor de vestir hábito sanjuanista y ser comendador administrador de la orden de Santiago.

Dejamos para el final al primogénito don Jorge Caamaño y Gayoso (1720-1771). Cursó en la Academia de guardiamarinas de Cádiz pero hizo carrera en el Ejército, alcanzando el grado de teniente coronel de caballería y el de capitán de carabineros de Su Majestad. En 1756, al año siguiente de morir su madre, última señora de Goiáns fallecida en el pazo homónimo, se desposó con doña María Ana de Sesma y Pontejos, integrante del influyente círculo navarro en la corte. Esta dama, hija de santiaguista, con un abuelo gentilhombre de Cámara y nieta de la Marquesa de Casa Pontejos, trajo al matrimonio una cuantiosa dote que rondaba los 2,5 millones de reales, en la que se incluía una colección de pintura valorada en 103.000 reales, y plata y diamantes tasados en más de 270.000 reales. Son indicadores de una escala de refinamiento cultural y lujo muy superior a la que presentaban la práctica totalidad de las residencias rurales y urbanas de la hidalga gallega y en particular las de don Jorge Caamaño. Prueba de ello es que la valoración conjunta de los efectos inventariados a la muerte de éste en su vivienda de Santiago, y los bienes y rentas de sus mayorazgos sumó 386.544 reales (186.913 en el caso particular de la casa de Goiáns y agregados a su administración).

En 1751 don Jorge Caamaño heredó estos vínculos de su padre don Juan Antonio Caamaño Varela, que a su vez, había sucedido en 1743 en el señorío de Goiáns a su tío materno el canónigo compostelano don Juan Antonio Varela. En menos de una década, el citado en segundo lugar tuvo tiempo para reorganizar y enriquecer el archivo de la casa de Goiáns, cuyo pazo se convirtió en su primera residencia, comprar decenas de parcelas de tierra en el Barbanza, invertir en pesca y tráfico marítimo y ampliar los negocios ganaderos de sus predecesores, con base en la riqueza de pastos de la isla de Sálvora ${ }^{4}$.

\section{LA ALIMENTACIÓN DE UNA ELITE}

Por lo dicho, se entiende pues que en la segunda mitad del siglo XVIII, los señores de Goiáns se moviesen en ámbitos de sociabilidad urbanos habiéndose desprendido por completo de los ropajes de la rusticidad. Su modo de vida y sus gustos eran los de una elite cada vez más desvinculada de sus solares rurales. Su preeminencia social y su poder se manifestaba de múltiples maneras, y en particular en la mesa, en nítido contraste con la pobre dieta de sus vasallos ${ }^{5}$. La alimentación de estas elites hidalgas cabe calificarla de hipercalórica, es decir desequilibrada aplicando parámetros nutricionales modernos, pero mucho menos monótona

${ }^{4}$ VÁZQUEZ LIJÓ (2012), opus cit.

5 Sobre la alimentación de la hidalguía, H. SOBRADO CORREA (2007). «El reino de las apariencias: El consumo conspicuo de la hidalguía gallega en la Edad Moderna». Noroeste. Revista de Historia, 3, (Actas do Congresso Internacional de História: Territorios, culturas e poderes, vol. II), pp. 470-472. 
que la popular. La propia explotación agrícola del pazo, la llamada granja, produjo una amplia variedad de frutos y frutas, algunos extraños a las tierras de los campesinos de los alrededores, caso de los espárragos, los melones o los garbanzos, una legumbre cuyo cultivo fue promovido por la efímera Real Academia de Agricultura de Galicia, de la que no fue socio el señor de Goiáns pero sí es muy posible que mantuviera contactos con alguno de sus miembros fundadores ${ }^{6}$.

El escaso peso, apenas un 7,4\% (1.314,5 reales) del capítulo alimentación ${ }^{7}$ en el conjunto de los gastos monetarios (17.651,5 rs.) de la casa de Goiáns en el cuatrienio 1776-1779 se explica por la apuntada condición del pazo como segunda residencia, ya entonces prácticamente vacío de vida. Obviamente este tipo de gastos en comida y bebida se disparaban con ocasión de las visitas, cada vez más esporádicas, de sus dueños, y más aún cuando se convidada a huéspedes distinguidos. En 1766 don Jorge Caamaño pasó una corta temporada en Goiáns a donde hizo llegar desde Madrid, donde estaba domiciliado, cuatro barriles de aceitunas y una cajita de rapé que este noble, como otros muchos, consumía ${ }^{8}$. Los días previos a la Navidad del año siguiente los pasó en su pazo de Romelle ejerciendo de anfitrión de su primo el Conde de Amarante a quien acompañó su cocinero particular, no escatimando gastos en comida (aceite sevillano, queso de Flandes, pescados selectos, capones...) y licores (Marie Brizard y Perfecto amor). El gasto en asistencias y manutención durante este corta estancia de apenas dos semanas superó los 1.700 reales $^{9}$, cantidad considerable pero muy inferior a los casi diez mil reales que costó atender en el otoño de 1807 al arzobispo compostelano Múzquiz y a su corto séquito, de visita pastoral, durante el mes que fue huésped en Goiáns. Acorde con su alta condición, al mitrado se le sirvieron platos de marisco, besugos y rodaballos, caros vinos de Jerez, perdices, garrapiñadas y un largo etcétera de artículos al alcance de muy pocos ${ }^{10}$.

Chocolateras, jícaras, molinillos y cafeteras denotan el consumo de artículos también propios de la mesa de los privilegiados. El caro chocolate, obsequio des-

${ }^{6}$ En agosto de 1767 el criado del Marqués de Viance visitó Goiáns por motivos desconocidos. Hacía menos de dos meses que había fallecido en Venecia don Tomás Suárez de Deza, titular de dicho marquesado, y miembro de varias academias, entre otras de la citada, y uno de los contadísimos nobles gallegos que realizó el Grand Tour. Apuntes biográficos de este noble lucense en J. NAYA PÉREZ (1957). «Una obra desconocida del arquitecto Domingo Lois Monteagudo. El palacio del Marqués de Viance, en Bóveda». Boletín de la Real Academia Gallega, 321-326, pp. 165-173. Sobre los fines y actuaciones da Real Academia de Agricultura A. M. ${ }^{a}$ SÁNCHEZ RODRÍGUEZ. (2003). «La agricultura gallega en la crisis del Antiguo Régimen: tentativas modernizadoras». Obradoiro de historia moderna, 12, pp. 225-227.

7 En la casa de Xunqueiras los gastos por dicho concepto supusieron un $1 / 3$ de los totales en 1734 y fueron del 24,5\% en el pazo de Oca en 1797. A. S. IGLESIAS BLANCO (2004). A Casa de Xunqueiras nos séculos XVIII e XIX. Valga: Concello de Valga, 2004, pp. 199, 294. P. SAAVEDRA (2003), «La vida en los pazos gallegos: entre la literatura y la historia». Pedralbes, pp. 308-309.

8 En el inventario hecho en su domicilio compostelano en 1771 se halló un bote con cuatro libras de tabaco en polvo. ADP, 1.180/10, 1.183/4. Uno de los objetos personales legados en 1800 por don Vicente Caamaño, sucesor de Jorge en el mayorazgo de Goiáns, a su primogénito fue una cajita de oro para rapé. ADP, 1.180/11.

9 ADP, 1.196/7.

10 ADP, $1.182 / 1$ 
de el tiempo de los Austrias ${ }^{11}$, entró con frecuencia y regularidad en la cocina del pazo de Goiáns donde en ocasiones se preparó por manos expertas ${ }^{12}$. Y estos hidalgos gallegos también degustaron café, de moda entre las clases altas de la segunda mitad del siglo XVIII. Considerado un gran estimulante del intelecto y de la creación, en un principio esta bebida se sirvió casi exclusivamente en las sobremesas de las grandes celebraciones ${ }^{13}$.

La situación excepcional del pazo facilitó las provisiones de alimentos marinos de calidad que en parte se obtuvieron de la pesquera que la casa de Goiáns estableció en la desembocadura del río Coroño ${ }^{14}$. Tanta o más importancia que esta pequeña reserva privada de pesca como fuente de proteínas de vigilia tuvo la ostrera de dicha zona, cuya explotación en exclusiva por parte de estos hidalgos fue vulnerada en varias ocasiones. De la de Goiáns, que no fue la única de dominio señorial en la ría de Arousa en aquellos siglos ${ }^{15}$, se extrajeron gran cantidad de ostras para abasto de las cocinas del pazo y tantas o más para regalar a los conventos donde profesaban las hijas de la casa. Algunas, sino todas, de las licencias de extracción concedidas a comunidades eclesiásticas, - grandes consumidoras de pescados y mariscos, frescos y, sobre todo, conservados ${ }^{16}$ - , fueron gratuitas y sin límites de capturas. Por el contrario, se cobró a los concesionarios que vendían el molusco ${ }^{17}$.

Estos cotos marisqueros dieron a sus dueños un producto económico escaso pero su valor simbólico no fue nada desdeñable. Prueba de ello es un incidente, lamentable por dar "qué decir al vulgo de él pays», que enfrentó a don Ignacio Abraldes, párroco de Lampón, con don Juan Antonio Caamaño. Se desencadenó en 1744 cuando criados de la casa quisieron prender a los que por orden del cura habían cogido unas pocas ostras. Caamaño le recordó a Abraldes que era beneficiado suyo, recriminándole por desconsiderado antes de autorizarle a extraer os-

${ }^{11}$ Barrionuevo en sus Avisos criticó la locura del duque de Alburquerque que gastó 50.000 reales en regalar 16.000 libras de chocolate a consejeros de la Monarquía y a otros poderosos. M. A. PÉREZ SAMPER. (2003). «Comer, beber y divertirse». En Vaca Lorenzo, A., Verdú Maciá, V [et. al.], Fiesta, juego y ocio en la Historia, Salamanca: Ediciones Universidad de Salamanca, p. 212.

12 En las detalladas cuentas de los gastos de la casa correspondientes al año 1758, se anota la compra de libras de azúcar, canela y arrobas de cacao para la fabricación de chocolate, y el pago a chocolateros. Con las rentas de Goiáns se costearon provisiones de chocolate para monjas que eran hijas de la casa. Por ejemplo, en el referido año se gastaron 808 reales por cuatro arrobas de cacao que se hicieron llegar a sor Juana de Dios, hermana del señor de Goiáns, que profesaba en el real convento madrileño de la Encarnación. ADP, 1.196/12.

${ }_{13}$ M. A. PÉREZ SAMPER (2001). "Chocolate, té y café. Sociedad, cultura y alimentación en la España del siglo XVIII». En Ferrer Benimeli, J. A., (dir.), El Conde de Aranda y su tiempo, Zaragoza: Instituto Fernando el Católico (CSIC), vol. I, pp. 157-221.

${ }^{14}$ ADP, 1.229/17, 18, 20.

${ }^{15}$ La mitra compostelana, el Conde de Monterrei y la casa de Fefiñáns figuran entre los pocos que tuvieron ostreras propias. A. MEIJIDE PARDO. (1969). «Notas históricas sobre la ostricultura en la Ría de Arosa». Cuadernos de Estudios Gallegos, tomo XXIV, n. ${ }^{\circ} 72-74$, pp. 463-488.

${ }^{16}$ Sobre esta cuestión J. M. VÁZQUEZ LIJÓ. (2009), «Sabrosa abstinencia. Abasto y consumo de pescado en el monasterio de Sobrado, siglos XVII-XVIII». Obradoiro de Historia Moderna, 18, pp. 151-179.

${ }_{17} \mathrm{Al}$ abad de San Martiño Pinario, que había pedido quince o dieciséis millares, se le permitió en 1728 «coger todas las ostrias que quisiere y hubiere». ADP, 1.180/3; 1.229/2, 3, 8, 9, 20. 
tras donde gustase. Lógicamente, el cura se mostró conciliador con el principal feligrés y presentero de su parroquia. Pero pidió que se delimitase la ostrera privativa de la casa de Goiáns pues «yo fuera de ella (...) quiero coger la que me haze menester, que hera muy puesto en razón que disfrute las regalías que me permite el término de mi curato, y así como en él puede echar la mar muchos cuerpos muertos apestados (lo que Dios no permita) para que de valde (...) y a costa de mis narizes los sepulte, es muy puesto en razón que me aproveche de el; y esto de los curatos creo que es como los foros que son echos a montes y fontes con que así no me puede faltar agua salada y dulce siendo así que en la mar ay muchos valdíos.... ${ }^{18}$.

Dicho privilegio de explotación ostrícola en toda la margen litoral del coto de Goiáns fue contravenido más de una vez por pescadores de la Ría de Arousa y originó un ruidoso pleito con el canónigo tenenciero de Boiro. A raíz de la entrada en vigor de la ordenanza de 1751, que concedía libertad de pesca a los matriculados de mar y sancionaba la jurisdicción exclusiva de Marina hasta donde llegaba el agua salada en las mayores pleamares, el mantenimiento de los privilegios en materia pesquera se condicionó notablemente y en ocasiones se hizo imposible. En la confirmación de la titularidad de dicho espacio a favor de la casa hidalga en cuestión, pesó tanto o más que la posesión inmemorial («que es el título más robusto que conoce el derecho») la condición de oficial de la Armada de don Vicente Caamaño, entonces señor de Goiáns. El y sus sucesores pudieron seguir explotando privativamente en ese litoral las ostras (pero no las demás especies) por mano de matriculados de mar y no, como hasta entonces, por criados suyos ${ }^{19}$.

Es bien sabido que las carnes y los dulces, en abundancia y de calidad, dieron notas de distinción a las mesas de las elites con ocasión de celebraciones o convites $^{20}$. Entre las primeras se prefirió la caza, y a este respecto, los señores de Goiáns gozaron de una importante reserva cinegética, particularmente de conejos, en su isla de Sálvora. Por otra parte, hay que tener en cuenta la provisión de pichones que garantizaba el palomar, uno de los componentes más característicos del ente físico del pazo gallego ${ }^{21}$. Como se constata en el Catastro de Ensenada muchas rectorales también contaron con palomar. Sin ir más lejos en la cercana de Santa Baia de Boiro, en la que se criaban cincuenta pares de palomas, las mismas que en el pazo de Goiáns desde donde en varias ocasiones se enviaron pichones para ser cocinados en las casas de sus dueños en Santiago o Ferrol ${ }^{22}$.

\footnotetext{
18 ADP, 1.229/22.

19 Sobre la controvertida exclusividad de los matriculados para practicar las actividades pesqueras, J. M. VÁZQUEZ LIJÓ (2005). La matrícula de mar y sus repercusiones en la Galicia del siglo XVIII. Santiago de Compostela: Servicio de Publicaciones de la USC, pp. 621-649.

20 Pérez Samper lo ha demostrado en diversos trabajos. Por ejemplo, M. A. PÉREZ SAMPER (1997). «La alimentación catalana en el paso de la Edad Media a la Edad Moderna». Pedralbes, 17, pp. 94-96.

${ }^{21}$ Recuérdese el refrán: «Palomar, capilla y ciprés, pazo es».

${ }^{22}$ Archivo del Reino de Galicia (ARG), Catastro de Ensenada, Real de Eclesiásticos, sig. 440, fol. 58v. ADP, 1.183/4, 1.181/9.
} 


\section{OCIO Y CULTURA}

Que el pazo dispusiese de un embarcadero de piedra facilitó la entrada y salida de productos por mar: ganado, materiales de construcción o vino, el género que en mayores cantidades fue enviado con regularidad a las residencias urbanas de los señores de Goiáns. Aquí atracaban tanto dornas, en las que las criadas del pazo iban a la cercana feria de la Merced a comprar tejidos y artículos de despensa, como algunas de las pinazas y pataches adquiridos por don Juan Antonio Caamaño y que mantuvo su sucesor ${ }^{23}$. Facilitar la carga y descarga de mercancías fue la principal razón de ser del embarcadero, pero su propia existencia también favoreció una actividad de ocio de los señores y de sus invitados, especialmente grata en época estival. Hablamos de cortos viajes de placer por el litoral de la Ría de Arousa y en particular con destino a la cercana granja de Esteiro ${ }^{24}$, en primera línea de playa, donde se levantaba una «bella casa» como la llamó el Padre Isla, alojado en Goiáns casi un mes durante el verano de $1755^{25}$. Estas breves travesías marítimas de ocio las realizarían en pequeños botes y dornas multifuncionales, nada más lejos de las reales falúas de Aranjuez, paradigma de las embarcaciones de aparato para diversión de los Borbones. Es relevador de esta práctica singular del tiempo libre por parte de las elites hidalgas con pazos limítrofes con la costa, las menciones, muy contadas, a barcos «de recreo» ${ }^{26}$. La mayoría de los identificados eran propiedad de don Apolinar Suárez de Deza, dueño de Mariñán, nieto paterno de don Vicente Caamaño Gayoso, el citado titular de la casa de Goiáns ${ }^{27}$.

Hay objetos que hablan de los aspectos lúdicos de estos señores. En 1674 se hallaron en el pazo dos lanzas de correr sortija, un juego ecuestre propio de caballeros como lo fue don Alonso Gómez de Rioboo ${ }^{28}$, coetáneo de don Juan Varela Mariño, señor de Goiáns y dueño de dichas armas. Otra diversión de gente de calidad era el toreo a caballo, para cuyo aprendizaje se editaron cartillas, una de

\footnotetext{
${ }^{23}$ Hay referencias a este tráfico de corto radio en las cuentas de diferentes años. ADP, 1.180/5, $1.181 / 10$.

${ }^{24}$ En el homónimo lugar del municipio de Boiro y dedicada fundamentalmente al cultivo de la vid. Esteiro pertenecía al mayorazgo de Romelle pero por razones de proximidad fue agregada a la administración de Goiáns desde que ambos vínculos fueron heredados por don Juan Antonio Caamaño en 1743.

25 J. F. ISLA. (1850). Obras escogidas del padre José Francisco de Isla, con una noticia de su vida y escritos por Don Pedro Felipe Monlau. Madrid: La Publicidad, pp. 437-440.

${ }^{26}$ Entre más de medio millar de embarcaciones matriculadas en la provincia marítima de A Coruña en la primera mitad del siglo XIX que se han documentado individualmente, sólo seis se califican de recreo. J. M. VÁZQUEZ LIJÓ. (2010). Labrando carballlos á beira do mar. Santiago de Compostela: Xunta de Galicia, Consellería do Mar, pp. 43.44.

27 J. A. SÁNCHEZ GARCIA (1999). Mariñán. Pazo de los sentidos, A Coruña: Editorial Diputación Provincial, 1999, páxs. 175-184. J. M. VÁZQUEZ LIJÓ. (2012). Luces...,

28 Descrito como «hombre de estraordinarias fuerzas corporales y que acometía lobos y jabalíes. Gran jinete y corredor de sortija, hera de intrépido natural y por eso muy temido en aquel país". Citado en J. A. SÁNCHEZ GARCÍA (2001), Torres do Allo: arquitectura e historia del primer pazo gallego. A Coruña: Deputación de A Coruña, p. 176. ADP, 1.200/11.
} 
las cuales formaba parte de la biblioteca del pazo en $1771^{29}$. En el inventario de este último año los nuevos hábitos de ocio estaban representados por un tablero de damas y por los naipes considerados por Jovellanos como honestos entretenimientos de «muchas personas de juicio y probidad en horas que son perdidas para el trabajo» ${ }^{30}$. El revesino debió ser del gusto particular de los hidalgos de esta casa, puesto que en la biblioteca se halló un manual de uso ${ }^{31}$. Y aquí se practicó además un esparcimiento deportivo al aire libre bastante popular en aquellos tiempos: el juego de boches, una variedad de petanca ${ }^{32}$. Cabe pensar que para entonces estos nobles, como tantos otros, habían imitado la moda cortesana de coleccionar pájaros $^{33}$, a la que fue tan aficionada Isabel de Farnesio y que se representó en pinturas tan conocidas como el delicioso retrato que Goya hizo del niño don Manuel Osorio, hijo de los Condes de Altamira, hoy en el Metropolitan de Nueva York. En el inventario de 1771 se anotaron dos jaulas para aves, quizás exóticas y de origen americano como lo fueron las juvencas traídas años antes de la Habana en la escuadra de Reggio para criar en Sálvora ${ }^{34}$.

Los instrumentos musicales, raros en los pazos gallegos en aquella época ${ }^{35}$, sonaron en Goiáns en la etapa de esplendor material que parece se vivía en 1755 cuando el Padre Isla gozó aquí de una placentera estancia. Los acordes ponían sintonía a las tardes de dolce far niente que disfrutaban los señores y su célebre invitado cuyo tiempo lo consumió «la música, la caza, la pesca, la mesa y la cama, después de cumplir con el breviario y con el misal lo más aprisa y lo peor que se puede» ${ }^{36}$. Pero la música no tardó en dar paso al silencio. En 1771 se halló un piano de manubrio «todo desenquadernado» y un viejo manicordio, falto ya de alguna cuerda que se almacenaba en una bodega junto a trastes de todo tipo ${ }^{37}$.

Por lo que concierne al mobiliario en general, el de Goiáns, como el del común de los pazos gallegos caracterizados por la austeridad de sus interiores, no fue

${ }^{29}$ Con alta probabilidad el tratado en cuestión sea la obra de Nicolás Rodrigo Noveli titulada Cartilla, en que se proponen las Reglas, para Torear a Caballo... (Madrid, 1726).

${ }^{30}$ M. $^{\text {a A }}$. PÉREZ SAMPER. (2003), p. 216. Sólo en el $9 \%$ de 340 inventarios postmorten consultados para la ciudad de Burgos aparecen juegos o mesas con este particular función. Por lo general se hallan en mansiones urbanas de la nobleza propietaria de regidurías perpetuas. De entre estos pasatiempos el más representado en los recuentos es el de las damas. F. J. SANZ DE LA HIGUERA (2005). «Lugares para el ocio en el Burgos del XVIII. Una aproximación socio-económica». Studia Histórica. Historia Moderna, 27, pp. 275-305.

${ }^{31}$ ADP, 1.183/4. Nos referimos a Modo christiano, político y cortesano de jugar bien al revesino... (Madrid, Imprenta de Juan de Moya, 1732), de Miguel de Armendáriz.

32 ADP, $1.196 / 12$.

${ }^{33}$ Sobre el coleccionismo de animales exóticos, de larga tradición en la corte española y que culmina en época borbónica, C. GÓMEZ-CENTURION JIMÉNEZ. (2009). «Los animales de América y Filipinas en la ménageire real en el siglo XVIII». Anuario de Estudios Americanos, 66, 2, pp. 181-211.

${ }^{34} \mathrm{La}$ carrera en la Armada de varios hijos de la casa de Goiáns facilitarían estos encargos en Indias. ADP, 1.183/4, 10.

${ }^{35}$ Sólo en uno de los 27 recuentos de bienes de pazos gallegos vaciados por V. M. Migués aparecen instrumentos musicales, en concreto dos arpas. V. M. MIGUÉS (2002), p. 360.

${ }^{36}$ ISLA, opus cit, p. 438.

37 ADP, 1.183/4. 
especialmente lujoso, aunque su calidad mejoró en el siglo XVIII ${ }^{38}$ respecto al inventariado en 1674 en paralelo al considerable aumento de las piezas decorativas en las que nos centraremos. En dicho recuento no se mencionaron sillas, armarios, mesas, camas ni bufetes de cedro, de palo rosa y de otras maderas de Indias (como la caoba y el granadillo), ni tampoco de charol inglés, a imitación de las lacas orientales con presencia en los de 1751 y $1771^{39}$. En el caso estudiado, al margen alguna que otra curiosidad ${ }^{40}$, la lista se reduce a unos pocos espejos y cortinas, contadas esculturas religiosas de pequeño tamaño y, sobre todo, cuadros de la misma temática.

El carácter devocional (el tema de la pasión de Cristo, la iconografía mariana, imágenes del santoral tradicional como San Pedro, San Jerónimo, San Juan Bautista...) fue denominador común de estas piezas artísticas. De 11 pinturas en 1674 se pasó a 20 en 1751, número superior a la media de las residencias rurales de la hidalguía gallega. Su estado de conservación era diverso y relativamente baja su tasación ${ }^{41}$.

Por su excepcional temática, entre los inventariados en 1751 hay que mencionar dos cuadros de «perspectivas de ruinas», es decir, paisajes con edificios clásicos destruidos que tuvieron amplia demanda entre las elites de la Europa de esa época pero suponían una rareza en un pazo ${ }^{42}$. En 1771 los cuadros se habían reducido a 14, la mayoría viejos y algunos «ajados» por el paso del tiempo, a cuyo cuidado no contribuía la deshabitación de la casa. El contraste de esta modesta colección artística con la selecta pinacoteca que, como parte de la dote de su esposa, don Jorge Caamaño pudo contemplar en su residencia madrileña resulta

${ }_{38}$ V. M. MIGUÉS. (2002). As terras, as pousas e os vinculeiros. A fidalguía galega na Época Moderna. A Coruña: Ediciós do Castro, pp. 358-363.

${ }^{39}$ Los muebles acharolados parecen haber tenido muy escasa presencia en las residencias hidalgas de la Galicia del siglo XVIII. A finales de dicha centuria, en la casa del Marqués de Almeiras en la ciudad de A Coruña sólo se halló un armario con ese acabado. E. SAMPAYO SEOANE (1997). «Un estudio sobre el entorno urbano de La Coruña del siglo XVIII, el ámbito de lo cotidiano». Obradoiro de Historia Moderna, 6, p. 277.

40 Novedades en 1771 respecto a dos décadas atrás fueron un par de figuras acharoladas, una con forma de pato de fábrica china, y otra todavía más extraña: una copa de una madera extranjera desconocida para el tasador y en su interior 65 vasos del mismo material y diferente tamaño encajados unos en otros. ADP, 1.183/4.

41 La más valorada lo fue en 300 reales, tres veces menos que el precio de tasación del mueble más lujoso del pazo: una cama de palo de rosa con torneado salomónico y colgadura de damasco encarnado presente en 1751 y 1771. ADP, 1.183/4, 12. Poco se sabe da demanda pictórica de la hidalguía galega en esa época. J. M. MONTERROSO MONTERO (1995). «La condición social del pintor en la Galicia de los siglos XVII y XVIII». Cuadernos de Estudios Gallegos, Tomo 42, fasc. 107, pp. 390-391.

42 Durante la Edad Moderna, las piezas artísticas de contenido profano escasearon mucho en las viviendas de la hidalguía gallega. Son de destacar las imágenes de sibilas y una pintura de montería hallados a mediados del siglo XVIII en el pazo de Noceda propiedad del Marqués de Astaríz, un rico comerciante ennoblecido en 1722, y los nueve bodegones y los tres retratos de reyes inventariados en 1798 en la ya citada lujosa mansión del Marqués de Almeiras. P. SAAVEDRA (1997). «Formación, consolidación e influencia social e cultural da fidalguía, ss. XVI-XVIII». En Pereira menaut, G. (coord..), O Feito Diferencial Galego na Historia. Historia: Santiago de Compostela: Museo do Pobo Galego, A Editorial da Historia, pp. 123-156. E. SAMPAYO SEOANE (1997), pp. 271-276. 
casi extremo. En ella colgaban obras, la gran mayoría del siglo XVII, atribuidas a grandes maestros; entre otras, retratos de Rubens, escenas de cacería de Frans Snyders, cuatro cuadros de devoción de Murillo, dos sobrepuertas con decoración floral del gran bodegonista Juan de Arellano, y un tondo de La Virgen con el Niño, de Urbina (sic), ¿un Rafael? valorado en 20.000 reales $^{43}$.

Modestamente, las bellas artes también estaban representadas en el pazo por 37 láminas, entre las que figuraba una curiosa estampa de Bernardo Gigli. Este hombre, gracias a su extraordinaria altura (2,6 metros) recorrió Europa como una especie de atracción de feria a la que don Jorge Caamaño tal vez asistió en Madrid donde esa celebridad fue exhibida ${ }^{44}$. En los inventarios de 1751 y 1771 no se hallaron pinturas representando a sus dueños. Estos retratos, signos de distinción y medios para conservar la fama, escasearon mucho en los pazos gallegos del siglo XVIII ${ }^{45}$. En 1800 se hallaron tres en el lujoso domicilio ferrolano de don Vicente Caamaño, sucesor del anterior como señor de Goiáns, que, es oportuno apuntar, demandó los servicios del célebre Melchor de Prado ${ }^{46}$. También entonces se inventariaron en la residencia urbana de este brigadier, Gran Cruz de la orden de Malta, 72 cuadros de caballeros sanjuanistas, una colección que tres décadas después, ya bastante incompleta y deteriorada, constituía el único elemento decorativo del pazo de Goiáns, desamueblado casi por completo y en muy mal estado de conservación ${ }^{47}$.

La biografía de don Juan Antonio Caamaño, nombre propio en el devenir de esta casa hidalga, y la de sus hijos, particularmente el mayorazgo, explica la existencia en el pazo de hasta diez mapas de diferentes reinos europeos (los escandinavos, Polonia, Gran Bretaña, Rusia, Italia, Francia ...) y determina parcialmente la composición de otro importante indicador cultural: la biblioteca. En 1751 ésta se componía de 204 tomos que fueron tasados en 2.100 reales, algo menos del salario anual del mayordomo del pazo. Algunos pasarían a ser propiedad de don Vicente Caamaño, entonces un joven alférez de navío, a quien su padre al testar

${ }^{43}$ Archivo General Militar de Segovia (AGM), C-1.132/exp. 8.767.

${ }^{44}$ Este acontecimiento de 1758 en la capital de España fue motivo de un breve impreso: El gigante portentoso: divertida noticia individual del peregrino joven de extraordinaria, y assombrosa estatura... Madrid: Imprenta de la Calle del Correo, Casa de las Armas, [1758?]. Biblioteca Nacional (BN), VE/1456/14/2

45 Una contada excepción fue el de Vilar de Ferreiros. P. SAAVEDRA. (1997). «Formación, consolidación e influencia social e cultural da fidalguía, ss. XVI-XVIII». En Pereira Menaut, G., O Feito Diferencial Galego na Historia. Santiago de Compostela: Museo do Pobo Galego, p. 141. El género del retrato cobró alguna importancia en la Galicia del siglo XVIII gracias sobre todo a la demanda de instituciones. El siglo de esplendor del retrato privado o burgués fue el XIX. Sobre la tipología del retrato en Galicia J. M. MONTERROSO MONTERO (1998). En El Retrato como imagen de una sociedad. Actas das V e VI Semanas Galegas de Historia: Morte e sociedade no noroeste peninsular. Santiago de Compostela: Asociación Galega de Historiadores, pp. 397-416.

${ }_{46}$ Que grabó su escudo de armas, impreso en algunos recibos de pago. Sobre este arquitecto, académico de Bellas Artes de San Fernando, F. PÉREZ RODRíGUEZ. (1997). «Datos para las biografías de los hermanos Manuel y Melchor de Prado y Mariño». Compostellanum, vol. 42, no 3-4, pp. 465-476.

47 ADP, 1.200/2, 1.180/11. VÁZQUEZ LIJÓ (2012). 
dispuso que «de los pocos libros que tengo, se tome los que quisiere y fuesen útiles a su profesión » ${ }^{48}$. Veinte años después esta librería contaba con 154 títulos, número superior a la media de las bibliotecas hidalgas de ese siglo y de principios del siguiente ${ }^{49}$. Junto a las habituales hagiografías y crónicas de personajes ilustres (Armas y triunfos de los gallegos glosados por Fr. Felipe de la Gándara compartía estante con una Vida de los Zares, y con otras biografías como la del cardenal Cisneros y la del príncipe Euxenio Francisco de Saboia) — para satisfacer la curiosidad de los caballeros que las leían, para entretenerse y, sobre todo, para reconocerse a sí mismo como elite-, se encontraban las siempre presentes guías para cuidado del alma (Retiro espiritual, los ejercicios de San Vicente Ferrer, catecismos, etc.). No faltaban clásicos griegos y latinos (Esopo, Virgilio, Cicerón ...) y castellanos (Góngora, Quevedo, Santa Teresa, el Guzmán de Alfarache ...), ni obras de historia y geografía, algún tratado de urbanidad, las ordenanzas de Caballería y las de la Armada, diccionarios y gramáticas de italiano y francés, la lengua de las ciencias y de las musas en la Europa de las Luces, y manuales de agricultura, de comercio y de moneda.

En suma, los inventarios de bienes y la documentación contable de la casa de Goiáns, entre otras fuentes, denotan el elevado estatus de sus dueños. El esplendor visible a mediados del siglo XVIII fue efímero pues no tardarían en hacerse visibles las huellas del abandono afectivo y físico que terminaría desmantelándolo durante largo tiempo, corriendo una suerte pareja a la de otros muchos pazos cuyo eclipse, novelado desde el realismo, la simpatía o la melancolía, según que autores, sirvió de marco de una imagen literaria estereotipada de hidalgo rudo e ignorante, muy alejada por perfil de los señores de Goiáns retratados en estas páginas a partir de su consumo cultural en sentido amplio ${ }^{50}$.

\footnotetext{
${ }^{48}$ ADP, 1.183710. AHUS, Protocolos notariales de Padrón. Benito Eiras Torrado, año 1751. Fol. 69v.

49 Aunque muy lejos de los 855 volúmenes de la inventariada en Noia a la muerte en 1803 de su propietario don Joaquín de Lamas Sotomayor, pariente cercano de los señores de Goiáns. M. FABEIRO GÓMEZ (1969). «Una Biblioteca noyesa de finales del siglo XVIII». Cuadernos de estudios gallegos, Vol. 24, pp. 571-577. La existente en 1709 en la residencia compostelana do Marqués de Santa Cruz de Ribadulla estaba constituída por 279 volúmenes. L. FERNÁNDEZ GASALLA (1995). «La Biblioteca de D. Andrés de Mondragón, I Marqués de Santa Cruz de Rivadulla, mecenas y político gallego del siglo XVII (1645-1709)». Cuadernos de estudios gallegos, T. 42, fasc. 107, pp. 449-564. A. PRESEDO. (2001). "Luxo e cultura nos pazos da fidalguía galega», Boletín Avriense, XXXI, pp. 143-164. Sobre la biblioteca del Marqués de Astariz en 1753, B. BARREIRO MALLÓN. (1981). «Las clases urbanas de Santiago en el siglo XVIII: definición de un estilo de vida y de pensamiento". En La Historia social de Galicia en sus fuentes de protocolos, Santiago de Compostela: Servicio de Publicaciones de la Universidad de Santiago de Compostela, pp. 491-492.

50 A este respecto P. SAAVEDRA. (2003). «La vida en los pazos gallegos: entre la literatura y la historia». Pedralbes, 23, pp. 287-290.
} 